\title{
QUALIDADE DO SERVIÇO PÚBLICO PARA EFETIVAÇÃO DE POLÍTICAS PÚBLICAS PARA O DESENVOLVIMENTO RURAL SUSTENTÁVEL: LEVANTAMENTO EM UMA COMUNIDADE PESQUEIRA LOCAL
}

\author{
Paulo Sérgio Almeida-Santos ${ }^{1}$ \\ Andreia Carpes Dani ${ }^{2}$ \\ José Luís Alves Araújo ${ }^{3}$ \\ José Matias-Pereira ${ }^{4}$
}

\begin{abstract}
RESUMO
Este artigo tem como objetivo identificar o nível de satisfação dos moradores da Colônia de Pescadores Z7, localizada no município de São Félix do Araguaia - MT, quanto aos serviços prestados pela empresa pública, EMPAER, a fim de aperfeiçoar qualidade dos trabalhos guiados por este órgão, na efetivação de políticas públicas de desenvolvimento rural sustentável no Estado mato-grossense. Os dados são coletados por meio de uma pesquisa de levantamento a partir de um questionário semiestruturado composto por 42 questões, tomando como base os instrumentos da Estrutura Comum de Avaliação - CAF. Em grande medida, os resultados obtidos, indicam uma percepção imparcial acerca dos serviços prestados pela EMPAER. O envolvimento e participação em programas de financiamento é dimensão, que carrega o maior nível de informação para análise da percepção geral dos moradores. Com efeito, as perspectivas referentes à obtenção de crédito por meio de programas de financiamento a agricultura rural, têm sido no momento, um dos principais pontos, que podem ser analisados minuciosamente pela entidade EMPAER.
\end{abstract}

Palavras-Chave: colônia de pescadores, desenvolvimento rural sustentável, economia familiar, políticas públicas, serviço público.

\footnotetext{
${ }^{1}$ Graduado em Ciências Contábeis (PUCPR). Mestrado em Ciências Contábeis (FURB). Doutorando em Ciências Contábeis (UnB). Professor e pesquisador da Faculdade de Administração e Ciências Contábeis da Universidade Federal de Mato Grosso (UFMT). E-mail: psalmeidasantos@ufmt.br.

${ }^{2}$ Graduada em Ciências Contábeis (URI). Mestrado em Ciências Contábeis (FURB). Doutoranda em Administração e Ciências Contábeis (FURB). E-mail: andreiacarpesdani@gmail.com.

${ }^{3}$ Graduado em Ciências Contábeis (UFMT). Especialista em Gestão Pública (UFMT). E-mail: joseluizsfa@gmail.com.

${ }^{4}$ Graduado em Ciências Econômicas (UNICEUB). Graduado em Direito (UNIDF). Mestrado em Planejamento Urbano (UnB). Doutorado em Ciências Políticas (UCM). Professor e pesquisador associado do Programa de Pós-graduação em Ciências Contábeis da Universidade de Brasília (UnB). E-mail: matias@unb.br.
} 


\title{
QUALITY OF PUBLIC SERVICE FOR PROMOTING SUSTAINABLE AGRICULTURE AND RURAL DEVELOPMENT: SURVEY ON A LOCAL FISHING COMMUNITIES
}

\begin{abstract}
The aim of this paper is to identify the level of satisfaction of the residents of the Colony of Z7 Fishermen localized in Sao Felix do Araguaia - MT, as the services provided by public company EMPAER in order to enhance quality of work guided by this body in the execution of policies public for sustainable rural development in Mato Grosso State. The data is collected through a survey from a semi-structured questionnaire composed of 42 questions, based on the instruments of the Common Assessment Framework - CAF. To a large extent, the results indicate an unbiased perception of services provided by EMPAER. The involvement and participation in funding programs is dimension, which carries the greatest level of information to analyze the overall perception of the residents. Indeed, the outlook related to obtaining credit through funding programs to rural agriculture, have been at the time, one of the main points, which can be scrutinized by EMPAER entity.
\end{abstract}

Keywords: colony of fishermen, family economy, public policy, public service, sustainable rural development.

\section{INTRODUÇÃO}

Nos últimos anos, os aspectos que orientam a modernização da agricultura no Brasil, impulsionada por fortes políticas agrícolas e também decisivas, tornaramse objeto de grandes debates (MARQUES, 2010). Assis (2006) pondera que o desenvolvimento rural sustentável deve ocorrer a partir de uma ação local, no qual os agricultores tenham condições de assumir a posição de atores primários.

Isso depende de decisões políticas, que procurem internalizar no sistema econômico, os danos à natureza, "ao mesmo tempo em que, por meio do uso de instrumentos de política agrícola e ambiental, seja estimulada a adoção, pelos agricultores, de modelos agroecológicos de produção, com destaque para os que utilizam estrutura de trabalho familiar" (ASSIS, 2006, p. 86). Acrescente-se a isto, que a agricultura é o principal instrumento propulsor do desenvolvimento de pequenas e médias cidades do interior do Brasil (SANTOS, 2001). Assim, novos incentivos a este setor, pode ensejar que outros setores dessas localidades se desenvolvam analogamente.

Em particular ao caso do Estado de Mato Grosso,este tem se destacado no cenário nacional, pelo seu grande potencial natural, bem como pelos avanços tecnológicos no agronegócio, sendo considerado como um dos principais Estados brasileiros com maior potencialidade na produção de grãos:soja, algodão etc., além de se destacar também no ramo agropecuário. Com efeito, atualmente, o agronegócio, é consideradoo esteio da economia mato-grossense,sendo, pois, a principal fonte geradora de emprego e renda (BRUM; LUFT, 2011; CAMPOS, 2010; NOGUEIRA, 2014).

Parte deste sucesso, mormente, deve-se ao empreendedorismo dos produtores locais, bem como de programas governamentais voltados ao desenvolvimento rural, tendo à frente, entidades, tais como a Empresa Matogrossense de Pesquisa, Assistência Técnica e Extensão Rural S/A (EMPAER), que 
busca atender a demanda que possa proporcionar aos produtores assistência integrada, nos aspectos da produção tecnificada e comercialização gerenciada (MORAES, et al., 2011; NOGUEIRA, 2014). Esta tem operado junto às secretarias de agriculturas dos municípios locais, "atendendo a produtores de assentamentos da reforma agrária, aldeias indígenas e hortas urbanas, executando trabalhos como assistência técnica agropecuária e elaboração de projetos de crédito rural" (LAFORGA; VIERA, 2008). Com efeito, a grande necessidade dos serviços de assistência técnica e extensão rural vivenciados no cenário mato-grossense,está relacionada a políticas governamentais direcionadas ao público de baixo poder aquisitivo, que estão inseridos nos modelos da nova Política Nacional de Assistência Técnica e Extensão Rural (ATER).

Nota-se que a missão da ATER está inclinada a chamada - ciência agroecologia - que se nutre dos saberes, conhecimentos e experiências dos: "agricultores (as), dos povos indígenas, dos povos da floresta, dos pescadores (as), das comunidades quilombolas, bem como dos demais atores sociais envolvidos em processos de desenvolvimento rural, incorporando o potencial endógeno", isto é, presente no "local" (CAPORAL et al., 2006).

A atividade de pesca artesanal (pesca de subsistência) mantém um cotidiano social orientado por uma relação profunda com a natureza, apresentando elementos culturais passados por diversas gerações, particulares em razão da estética territorial única, cuja determinação ambiental fez surgir um núcleo cultural particular. Destarte, a produção agrícola "é sempre, em maior ou menor grau, assegurada pela exploração familiar e que o produtor familiar não possui único padrão cultural, social e econômico, mas difere entre si intensamente, faz-se necessário estudá-lo em suas várias formas" (GOMES, 2005, p. 2).

Interligando as políticas públicas às questões ambientais, Hellebrandt (2012) esclarece que as políticas de promoção à pesca, influenciam no aumento da captura do pescado, e devido a esse recurso natural ser renovável, possui características de bem público, e por ser de difícil imposição de direitos de propriedade, sua existência pode ser ameaçada pela pesca excessiva.

Hellebrandt (2012) a partir de um levantamento realizado sobre os estudos nacionais que abordam - políticas públicas aplicadas ao setor pesqueiro - infere que até o final da década de 1990, havia diversas pesquisas análogas, p. ex., a de Abdallah (1998) ${ }^{1}$; embora essa situação tenha se alterado com a redução drástica a partir do ano de 2000 (HELLEBRANT, 2012). Oportunamente, percebe-se uma lacuna científica no que tange este setor, que tanto está relacionado à agricultura familiar quanto ao desenvolvimento de políticas específicas para o setor pesqueiro. Por exemplo, a exploração pesqueira de forma artesanal por pescadores credenciados e associados à colônia $Z 7$, unidade de investigação deste estudo, é essencial para o sustento alimentar das famílias ribeirinhas de moradores que vivem às margens dos rios, e possuem princípios herdados e presentes na atividade rotineira das famílias.

Diante do que brevemente é ponderado, e utilizando-se do instrumento de avaliação comum de avaliação $(\mathrm{CAF})^{2}$ para levantamento quanto à satisfação dos

\footnotetext{
${ }^{1}$ Abdallah (1998) analisou a evolução da atividade pesqueira no Brasil entre os anos de 1960 a 1994. Na oportunidade constatou que a quantidade produzida de pescado, embora com algumas oscilações durante 0 período, apresentara uma ascensão razoável, sofrendo declínio a partir do último ano investigado.As regiões Sul e Sudestes foram aquelas que se destacam sobre as demais regiões quanto à produção em relevo.

2 A CAF (Common Assessment Framework) é um modelo europeu que serve para avaliar e melhorar o desempenho organizacional, tendo como referência os princípios da Excelência. O modelo CAF é específico para o setor público e a sua utilização é gratuita. Cerca de 3600 organizações públicas europeias já utilizam a CAF. O modelo CAF baseia-se no pressuposto de que as organizações atingem resultados excelentes
} 
serviços oferecidos por entidades públicas, a questão-problema a ser respondida,é:Qual o nível de percepção de uma colônia de pescadores referente aos serviços prestados por uma empresa pública no tocante à (a) imagem global, (b) ao envolvimento e participação em programas de financiamento, (c) às condições de acessibilidade, e (d) aos produtos e serviços ofertados?

Nesta perceptiva, busca-se identificar o nível de satisfação dos moradores da Colônia de Pescadores Z7, localizada no município de São Félix do Araguaia MT, quanto aos serviços prestados pela EMPAER, a fim de aperfeiçoar qualidade dos trabalhos guiados por este órgão na efetivação de políticas públicas de desenvolvimento rural sustentável no Estado mato-grossense.

No contexto econômico e social do País, é imprescindível estabelecer políticas públicas, dando condições infraestruturais básicas que atendam às necessidades de todos os produtores rurais locais, que buscam retirar o seu sustento da própria natureza, e assim dar continuidade ao sistema de produção em escala comercial de maneira sustentável, digna, ambientalmente legal e responsável. Conforme explica Hellebrandt (2012), as políticas empregadas pelo governo no setor pesqueiro podem implicar na geração, ampliação ou minimização dos conflitos provocados pela atividade pesqueira.

Diante do exposto, a pesquisa justifica-se tendo em vista a influência das políticas públicas na manutenção da atividade e sobrevivência dos pescadores artesanais, desenvolvimento da região envolvida e a escassez de estudos realizados em âmbito nacional, principalmente voltados ao Estado do Mato Grosso.

Assim, espera-se que este trabalho contribua para o desenvolvimento de boas práticas de assistência técnica a partir de políticas públicas eficazes, que atendam as reais necessidades da comunidade pesquisada (comunidades ribeirinhas), considerando-se, sobretudo, as especificidades ambientais da região e o desenvolvimento das atividades da comunidade, baseadas na equidade e na sustentabilidade. $O$ instrumento de avaliação da CAF utilizado para medir a qualidade dos serviços prestados pela EMPAER é muito oportuno para esse diagnostico. Destarte, busca-se, nomeadamente, contribuir para discussão acadêmica sobre o tema "aumentando o conhecimento sobre a implementação de lógicas de autoavaliação e de gestão de qualidade em organismos públicos, bem como suscitar o interesse pela utilização destas novas abordagens". (AGUIAR, 2010, p. 12).

\section{REVISÃO BIBLIOGRÁFICA}

\subsection{DESENVOLVIMENTO SUSTENTÁVEL E ECONOMIA FAMILIAR NO BRASIL}

$\mathrm{Na}$ maioria dos países, são os estabelecimentos agrícolas familiares aqueles capazes de acolher os sistemas de produção inspirados na agroecologia e que estão em conformidade com as exigências de desenvolvimento sustentável (MARQUES, 2010).

O desenvolvimento sustentável busca a melhoria da qualidade de vida humana dentro dos limites da capacidade de suporte dos ecossistemas (ASSIS, 2006). No Brasil "a opção pela agricultura familiar justifica-se por sua capacidade de geração de emprego (da família e de outros) e renda a baixo custo de investimento", além de influenciar na retenção da população fora dos grandes centros urbanos,

aonível do desempenho na perspectiva dos cidadãos/clientes, colaboradores e sociedade quando têm lideranças que conduzem a estratégia, o planeamento, as pessoas, as parcerias, os recursos e os processos. (http://www.caf.dgaep.gov.pt/). 
auxiliando na construção de alternativas de desenvolvimento (SANTOS, 2001). A "alta flexibilidade de adaptação a diferentes processos de produção e a variedade de fontes de renda tornaram a agricultura familiar elemento fundamental da modernização agrícola e, particularmente, de certas cadeias agroindustriais" (GOMES, 2005, p. 2).

Santos e Santos (2005) ressaltam que o ponto principal a considerar quando se evoca a sustentabilidade do setor pesqueiro é que a redução dos estoques de pescados, e demais efeitos negativos que existem, não surgem exclusivamente em virtude da pesca, mas de impactos contraproducentes do entorno, como a derrubada das matas ciliares, a destruição de nascentes, o assoreamento, a poluição e o represamento de rios. Nesse contexto, destaca-se que existem aspectos relacionados à sustentabilidade ecológica e social, além da visão econômica (SANTOS; SANTOS, 2005).

A sustentabilidade ecológica, diz respeito ao equilíbrio e manutenção de ecossistemas, à conservação de espécies e à manutenção de um estoque genético das espécies, que garanta a resiliência ante aos impactos externos. Já a sustentabilidade social, ressalta a importância da participação social e do aumento das potencialidades e qualidades das pessoas na construção de um futuro mais justo. Notadamente, tem havido um avanço na concepção de sustentabilidade social no que tange à noção de desenvolvimento sustentável, passando de uma postura que associava pobreza à degradação ambiental, a uma que utiliza a participação na cogestão dos recursos visando atingir a sustentabilidade (FOLADORI, 2002).

Durante os últimos trinta anos, a questão central da sustentabilidade social diz respeito à redução da pobreza e o incremento populacional, além de contribuir para questões como equidade e qualidade de vida.De modo geral, os mecanismos e as agências que promovem o desenvolvimento sustentável podem conduzir a melhorias locais de alto impacto sobre a população, mas também são essenciais para efeitos de direitos humanos, assim como solucionam problemas específicos de fome ou doenças (FOLADORI, 2002, p. 112).

Ferro et al. (2003, p. 8) ressaltam a necessidade de se implantar "uma política agrícola diferenciada em regime de economia familiar, com foco em melhorar a qualidade dos alimentos produzidos por pessoas envolvidas no processo, não havendo necessidade de adquiri-los fora da propriedade. " Consequentemente, a capacidade de produzir alimentos a menor custo e, potencialmente, com menores danos ambientais, impulsiona o crescimento de todo o entorno socioeconômico local (SANTOS, 2001).

As políticas ou programas diferenciados de desenvolvimento "são usualmente dirigidos a segmentos empobrecidos do campesinato, não integrados à modernização produtiva, e muitas vezes assumem ou assumiram, como no Brasil, um caráter de políticas de desenvolvimento regional" (DELGADO, 2001, p. 26-27).

As políticas de apoio à agricultura familiar devem integrar atividades nãoagrícolas, como a industrialização, produção artesanal, turismo rural, e outras atividades voltadas à geração de renda e ocupação, priorizando "investimentos públicos para garantir serviços de pesquisa, experimentação, difusão, assistência técnica e extensão rural, comprometidos com a sustentabilidade e adaptados aos meios de produção familiar." (SANTOS, 2001, p. 230).

Para que o processo de desenvolvimento possibilite a manutenção ou aumento, ao longo do tempo do conjunto de bens econômicos, ecológicos e socioculturais, é necessário atuar de forma interdependente ao crescimento econômico, justiça social e conservação dos recursos naturais (ASSIS, 2006, p. 81).

O crescimento econômico é percebido quando a produção está atingindo outros mercados e trazendo melhoria na qualidade de vidas das pessoas envolvidas 
no processo. Isso ocorre utilizando-se de tecnologias a custo baixo, aplicando projetos de forma integrada e verticalizada, otimizando a mão-de-obra utilizada etc. (FERRO et al., 2003, p. 13). Estes autores ponderam ainda que, no decorrer desta fase, observa-se uma visão ampla que ocorre quando esse produtor acredita que sua oferta poderá chegar à mesa de várias famílias, e pode competir com o mercado consumidor.

Azevedo e Pierre (2014), defendem que sendo efetivamente implementadas, as normas e legislações podem melhorar em alguma medida as condições de vida dos pescadores artesanais, e consequentemente a manutenção da sustentabilidade dos recursos. Assim, o reconhecimento da interdependência entre sistemas naturais e econômicos depende de reformulações no sistema de valores da sociedade e das políticas públicas direcionadas a um desenvolvimento que pretende ser sustentável (CHAMY; MALDONATO, 2003).

Tendo em vista que, a definição de instrumentos econômicos voltados à diminuição das desigualdades sociais e sua compatibilização ao conhecimento que comunidades locais possuem sobre seus territórios é imprescindível para que políticas públicas voltadas à sustentabilidade tenham sucesso (CHAMY; MALDONATO, 2003), discute-se na sessão seguinte as políticas públicas aplicadas ao setor pesqueiro brasileiro, no âmbito da economia familiar rural.

\subsection{POLÍTICAS PÚBLICAS APLICADAS AO SETOR PESQUEIRO}

Notadamente a agricultura familiar é responsável por grande parte da produção de alimentos básicos em todo mundo;no Brasil, passa-se por um período de crise estrutural, com necessidades sociais graves, que resulta na exclusão do produtor familiar do processo produtivo e até mesmo sua expulsão do meio rural (FERRO et al., 2003, p. 7). A vida do homem do campo em decorrência da exploração do trabalho rural requer atenção especial, bem como acompanhamento e incentivos por parte de políticas públicas voltadas as suas necessidades. Logo, a política pública traz dentro do contexto dos programas uma proposta da eficácia na vida humana. Segundo Campos(2010) torna visível a análise de política pública como objetivo de solucionar conflitos outrora ocorridos.

As atividades de pesca artesanal contrastam com um cenário marcado pelo viés produtivista, predominando a utilização de um conjunto diversificado de técnicas eficientes e de baixo impacto sobre os ecossistemas (REBOUÇAS et al., 2006).Entre os tipos de pesca existentes, destacam-se a pesca industrial e a pesca artesanal. Embora "a pesca industrial movimente a maior parte da economia advinda desta atividade, a pesca artesanal tem inegável importância social ao envolver a maior parte desta população" (HELLEBRANDT et al., 2012, p. 2). A sobrevivência do pescador artesanal "na atividade pesqueira, tendo em vista a característica da pesca artesanal e do pescador artesanal, depende do seu próprio conhecimento, de suas habilidades e da conservação dos recursos pesqueiros" (SOUZA, 2001, p. 9). Assim, torna-se essencial a criação de políticas e programas voltados para a distribuição de renda, tendo em vista que "os problemas do campo são de ordem econômica, de acessos aos mercados e de políticas voltadas para o desenvolvimento das suas populações" (SANTOS, 2001, p. 226).

Hellebrandt (2012, p. 28) salienta que "dentre as políticas de promoção da atividade pesqueira, estão os benefícios fiscais às atividades do setor, e a possibilidade de crédito rural, além de outros instrumentos econômicos de promoção ao desenvolvimento do setor".Ao analisar a eficácia das atuais políticas, Hellebrandt (2012, p. 92) constatou "que o esforço governamental em promover a inclusão social do pescador artesanal, através da geração de emprego e renda, pode resultar num 
efeito contrário, incentivando o inchaço de pescadores e o consequente aumento da pressão sobre os estoques pesqueiros". Para Hellebrandt (2012) a relação entre as políticas públicas e o setor pesqueiro brasileiro, transitou por diversas etapas. $\mathrm{Na}$ Figura 1 é apresentada uma breve síntese da evolução histórica das ações dos governos brasileiros relacionadas ao desenvolvimento do setor pesqueiro.

Figura 1 - Evolução histórica das ações do governo brasileiro relacionadas ao desenvolvimento do setor pesqueiro

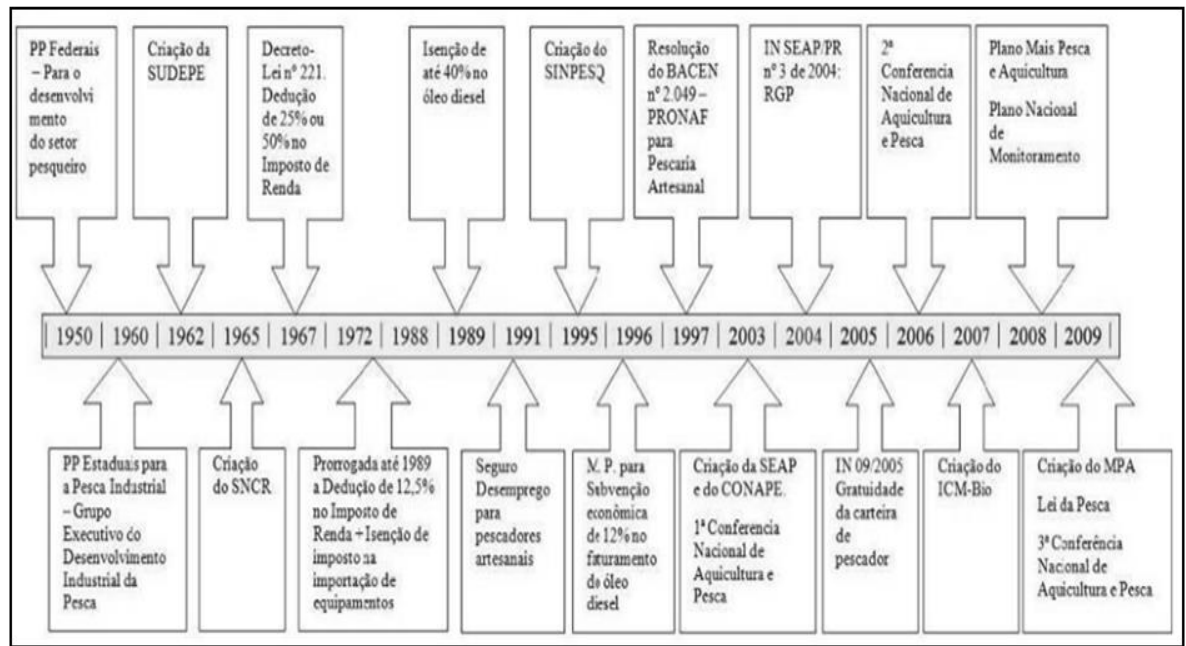

Fonte: Hellebrandt (2012, p. 92).

Hellebrandt (2012) estabelece um contraponto entre a primeira fase (1950 2000) foi voltada ao desenvolvimento do setor pesqueiro nacional através de benefícios fiscais e fase atual (pós ano 2000), voltada à preocupação social, com a valorização das questões ambientais, com valorização da gestão dos recursos naturais e segurança alimentar.

Dentre os eventos apresentados no estudo de Hellebrandt (2012), ressaltase que a partir do ano de 1950 ocorreu o início das políticas nacionais voltadas a setores com peculiaridades específicas, a exemplo do pesqueiro; e nos anos seguintes com a criação de institutos e órgãos voltados ao desenvolvimento industrial da pesca, por meio de convênios, pesquisas etc. Na década de 1990, começaram a atuar também políticas públicas estaduais. Após o ano de 2000 , foi marcado por uma nova postura do Governo Federal em relação ao setor pesqueiro, através da criação do CONAPE (Conselho Nacional de Aquicultura e Pesca), e realização da primeira Conferência Nacional de Aquicultura e Pesca na qual fora lançado o Plano Estratégico de Desenvolvimento Sustentável da Aquicultura e Pesca, e em seguida realizando-se implementações de várias novas linhas de crédito e outros benefícios fiscais para o setor.

Releva destacar que nesta perspectiva o Estado do Mato Grosso, destacase no tocante às políticas de assistência rural, de modo especial, sublinhando-se aquelas implantadas no município de São Félix do Araguaia desde o final dos anos 70. Essas políticas buscam avultar a produção agrícola associada à qualidade de vida dos moradores das comunidades rurais locais, por meio de serviços que 
envolvem desenvolvimento tecnológico, campanhas sociais de saúde, educação, economia doméstica etc.

A abrangência do serviço de assistência aos trabalhadores rurais na área de atuação do projeto MDA (Secretaria Especial de Agricultura Familiar e do Desenvolvimento Agrário) /ATER (Comunidade Colônia dos Pescadores Z7) é tida como uma política pública do Governo Federal, voltada à classe de baixa renda de produtores que estão fora do cadastro do Instituto Nacional de Colonização e Reforma Agrária (INCRA), ou seja, não foram beneficiados por programas de reforma agrária.

A Constituição Federal (1988) fixa que as políticas agrícolas contemplem em especial os serviços de ATER, mas em 1989 o executivo do Estado extinguiu o órgão máximo de ATER, através do decreto lei n. 97.455 (15 de janeiro de 1989), conhecido como Operação Desmonte.

Em linhas gerais no Brasil, a política nacional voltada ao setor pesqueiro estruturou-se em três eixos caracterizados de desenvolvimento sustentável da pesca, desenvolvimento sustentável da agricultura e gestão da política pesqueira. "As ações desses programas objetivam subsidiar as políticas de ordenamento e desenvolvimento da cadeia produtiva da pesca e agricultura" (HELLEBRANDT, 2012, p. 32).Tendo em vista a importância das políticas públicas para o setor pesqueiro e os serviços prestados pela EMPAER-MT à colônia de pescadores Z7 do município de São Félix do Araguaia, torna-se oportuno investigar qual a satisfação dos pescadores com os serviços prestados por esta entidade, motivação pela qual se realiza este estudo.

\section{MÉTODO}

A pesquisa é delineada como descritiva, do tipo levantamento com abordagem "quali-quanti" da sua situação-problema.

\subsection{POPULAÇÃO E AMOSTRA}

A população da pesquisa diz respeito aos pescadores assistidos pela EMPAER na Colônia - Z7. Esta colônia de pescadores está localizada no município de São Félix do Araguaia as margens do Rio Araguaia no Estado do Mato Grosso, em frente à Ilha do Bananal, sendo fundada em 28 de abril de 1.989, com 75 sócios, conforme ilustra a Figura 2.0 mandato da sua diretoria dar-se mediante eleições e tem a duração de dois (2) anos. A diretoria é formada por presidente, secretário, tesoureiro e conselheiro fiscal. A criação da sede se deu no primeiro semestre de 2002, em sistema de mutirão regido pelo presidente que ocupou o cargo de dois mandatos consecutivos.

A EMPAER é dotada de personalidade jurídica de direito privado, possuindo como acionista majoritário o Governo do Estado com $97,43 \%$ das ações, a EMBRAPA (2,56\%) e Terceiros ( $0,01 \%)$. Atua no Estado de Mato Grosso há mais de 45 anos, com sede localizada na capital do Estado (Cuiabá), possuindo extensões com escritórios locais em 128 Municípios, sendo uma sede escritório Central, nove escritórios Regionais, quatro escritórios locais distritais, quatro viveiros de produção de mudas, seis campos experimentais, seis centros regionais de pesquisa e transferência de tecnologia e um campo experimental.

O público da Colônia - Z7 corresponde a uma população de 42 (quarenta e dois) pescadores ativos e inativos. Para esta pesquisa foram considerados apenas os pesadores ativos, tendo em vista às condições de acesso à localidade na qual residem os ribeirinhos. Dessa forma, foram entregues 25 (vinte e cinco) 
questionários. O número de questionários entregues correspondeu a 59,52\% da população, retornando uma amostra final válida de 21 questionários respondidos.

Os morados da Colônia vivem basicamente da pesca artesanal das espécies de peixes originadas na bacia hidrográfica do Araguaia. Atualmente existem apenas 42 pescadores ativos que exploram a atividade pesqueira como forma de economia familiar.

A "Lei no. 9.893 de 01 de março de 2013 limita o período da pesca ao pescador profissional, de 01 de abril a 01 de outubro, permitindo a este capturar semanalmente $125 \mathrm{~kg}$ de pescados com a guia de DPI - Declaração Individual de Pesca, enquanto ao portador da carteira ou pescador amador, ficou permitido a captura de até $3 \mathrm{~kg}$ (três quilos) e um exemplar".

Figura 2 - Colônia de Pescadores Z7 do Município de São Félix do Araguaia/MT

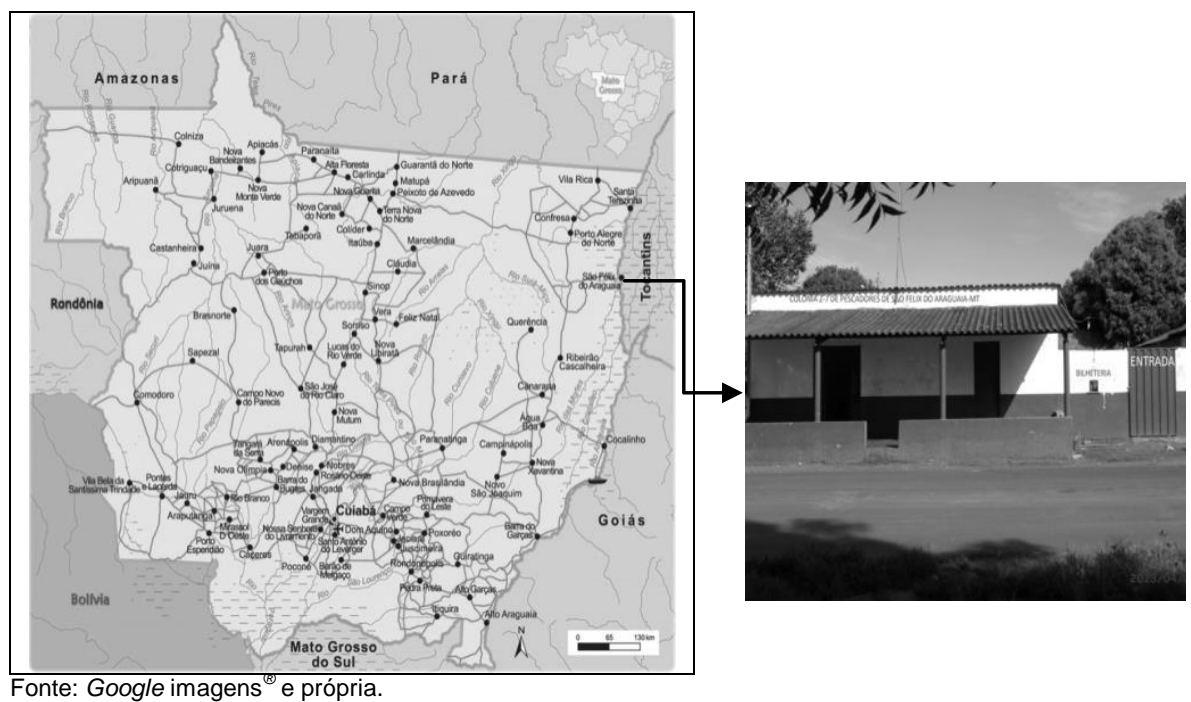

\subsection{COLETA DOS DADOS}

Para a coleta dos dados, é feito uma adaptação de um questionário semiestruturado, dividido em quatro categorias diferentes. O questionário aplicado foi ajustado da CAF - Estrutura Comum de Avaliação. Trata-se de um instrumento bastante utilizado para avaliação de organizações governamentais na Europa.

$O$ instrumento de pesquisa foi entregue pessoalmente a cada um dos entrevistados. Quando realizada a coleta dos dados, preocupou-se em situar o respondente a respeito da maneira que essas informações pretendem atingir o objetivo de solucionar o problema com a resposta obtida. Tal procedimento foi utilizado com vistas a facilitar a coleta de dados juntos aos respondentes, considerado, na percepção dos pesquisadores como "pessoas simples com baixo grau de instrução".

Optou-se pela formulação de um questionário semiestruturado por categorias, utilizando-se uma escala likert de cinco pontos que indica o grau de satisfação dos participantes da pesquisa, com os itens investigados (Quadro 1), 
sendo a escala utilizada: $1=$ muito insatisfeito; $2=$ insatisfeito; $3=$ indiferente; $4=$ satisfeito;e $5=$ muito satisfeito.

Quadro 1 - Categorias do instrumento de pesquisa

\begin{tabular}{|l|c|c|}
\hline Blocos de Investigação Além do Perfil dos Respondentes (1) & Mensuração & $\begin{array}{c}\text { No. } \\
\text { Questões }\end{array}$ \\
\hline B1-Imagem Global da Organização & Escala likert & 06 \\
\hline B2 - Envolvimento e Participação Programas de & Escala likert & 09 \\
Financiamento & Escala likert & 10 \\
\hline B3 - Acessibilidade à Empresa & Escala likert & 11 \\
\hline B4- Produtos e Serviços Ofertados pela Empresa & 36 \\
\hline \multicolumn{2}{|c|}{ Total }
\end{tabular}

Fonte: Adaptado da CAF - Estrutura Comum de Avaliação.

Do total de 42 questões, estas 36 referem-se a aspectos específicos relacionados ao grau de satisfação de diversos elementos envolvidos na prestação de serviço da EMPAER no município. Os dados foram coletados entre os meses de maio a setembro de 2014, conforme a disponibilidade dos respondentes. Cabe ressaltar que a pesquisa se torna oportuna especialmente nesse período, considerando que a quantidade de pescadores pertencentes à colônia encontra-se em declínio contínuo, e os resultados podem auxiliar a identificar alguns dos elementos que podem estar relacionados a este fato.

É utilizado das estatísticas descritivas para análise dos dados. Adicionalmente é aplicado, primeiramente o teste de alpha de Cronbach a fim de verificar a fiabilidade das respostas obtidas, além disso, a análise das componentes principais (ACP) com intuído de verificar dentre os blocos de questões, aquela que carrega o maior peso de informação, que possibilite uma conclusão geral sobre a percepção dos entrevistados.

\section{RESULTADOS E DISCUSSÕES}

Ilustram-se inicialmente na Tabela 1, as estatísticas descritivas inerentes às respostas relativas ao - perfil dos respondentes. Em sua grande maioria, são do gênero masculino, têm idade entre 46 e 55 anos, são casados, ou estão em um estado civil análogo a este. Grande parte deles possui o ensino fundamental completo. Todos os pescadores residem na Colônia, há mais de 10 anos, e tem como atividade laboral primária, notoriamente a pesca, que consiste neste caso, o único meio de subsistência de suas famílias. 
Tabela 1 - Perfil dos respondentes

\begin{tabular}{|c|c|c|c|c|c|c|c|c|c|c|c|c|c|}
\hline \multicolumn{14}{|c|}{ Painel A: Gênero, idade, estado civil e nível de escolaridade } \\
\hline Gênero & $F i$ & $f i$ & Idade & $F i$ & $f i$ & \multicolumn{2}{|c|}{ Estado Civil } & $\mathrm{Fi}$ & fi & \multicolumn{2}{|c|}{$\begin{array}{c}\text { Nível de } \\
\text { Escolaridade }\end{array}$} & $\mathrm{Fi}$ & fi \\
\hline $\begin{array}{c}\text { Feminin } \\
0\end{array}$ & 6 & $\begin{array}{l}29 \\
\%\end{array}$ & $\begin{array}{l}<25 \\
\text { anos }\end{array}$ & 1 & $5 \%$ & \multicolumn{2}{|c|}{ Solteiro (a) } & 5 & $\begin{array}{l}24 \\
\%\end{array}$ & \multicolumn{2}{|c|}{ Analfabeto } & 2 & $\begin{array}{l}10 \\
\%\end{array}$ \\
\hline $\begin{array}{l}\text { Masculi } \\
\text { no }\end{array}$ & 15 & $\begin{array}{l}71 \\
\%\end{array}$ & 26 a 35 & 0 & $0 \%$ & \multicolumn{2}{|c|}{$\begin{array}{l}\text { Divorciado } \\
\text { (a) }\end{array}$} & 1 & $5 \%$ & \multicolumn{2}{|c|}{ Ensino Primário } & 7 & $\begin{array}{l}33 \\
\%\end{array}$ \\
\hline & & & $\begin{array}{c}36 \text { a } 45 \\
\text { anos }\end{array}$ & 3 & $\begin{array}{l}14 \\
\%\end{array}$ & \multicolumn{2}{|c|}{$\begin{array}{l}\text { Separado } \\
\text { (a) }\end{array}$} & 1 & $5 \%$ & \multicolumn{2}{|c|}{$\begin{array}{c}\text { Ensino } \\
\text { Fundamental }\end{array}$} & 9 & $\begin{array}{l}43 \\
\%\end{array}$ \\
\hline & & & $\begin{array}{l}46 \text { a } 55 \\
\text { anos }\end{array}$ & 9 & $\begin{array}{l}43 \\
\% \\
\end{array}$ & \multicolumn{2}{|c|}{ Viúvo (a) } & 0 & $0 \%$ & \multicolumn{2}{|c|}{ Ensino Médio } & 1 & $5 \%$ \\
\hline & & & $\begin{array}{l}>56 \\
\text { anos }\end{array}$ & 8 & $\begin{array}{l}38 \\
\%\end{array}$ & \multicolumn{2}{|c|}{$\begin{array}{c}\text { União } \\
\text { Estável }\end{array}$} & $\begin{array}{l}1 \\
1\end{array}$ & $\begin{array}{l}52 \\
\%\end{array}$ & \multicolumn{2}{|c|}{ Ensino Técnico } & 1 & $5 \%$ \\
\hline & & & & & & \multicolumn{2}{|c|}{ Casado (a) } & 3 & $\begin{array}{l}14 \\
\%\end{array}$ & \multicolumn{2}{|c|}{ Ensino Superior } & 1 & $5 \%$ \\
\hline \multicolumn{14}{|c|}{ Painel B: Tempo de residência, principal atividade desenvolvida na colônia } \\
\hline \multicolumn{5}{|c|}{ Tempo de Residência na Colônia } & Fi & fi & \multicolumn{4}{|c|}{$\begin{array}{c}\text { Principal Atividade } \\
\text { Desenvolvida na Colônia }\end{array}$} & Fi & & fi \\
\hline \multicolumn{5}{|c|}{$<1$ ano } & 0 & $0 \%$ & \multicolumn{4}{|c|}{ Aposentado } & 0 & & $0 \%$ \\
\hline \multicolumn{5}{|c|}{1,6 a 3 anos } & 0 & $0 \%$ & \multicolumn{4}{|c|}{ Pescaria } & 17 & & $31 \%$ \\
\hline \multicolumn{5}{|c|}{3,6 a 5 anos } & 0 & $0 \%$ & \multicolumn{4}{|c|}{$\begin{array}{l}\text { Serviço Braçal } \\
\text { (mensalista) }\end{array}$} & 4 & & $9 \%$ \\
\hline \multicolumn{5}{|c|}{5,6 a 9 anos } & 0 & $0 \%$ & \multicolumn{4}{|c|}{ Diarista } & 0 & & $0 \%$ \\
\hline \multicolumn{5}{|c|}{$>10$ anos } & 21 & $100 \%$ & \multicolumn{4}{|c|}{ Comerciante } & 0 & & $0 \%$ \\
\hline & & & & & & & \multicolumn{4}{|c|}{ Outro } & 0 & & $0 \%$ \\
\hline
\end{tabular}

Fonte: dados da pesquisa.

É destacado ainda que por meio do teste de confiabilidade (Alpha de Cronbach's), procurou-se identificar a confiabilidade do instrumento de pesquisa utilizado na coleta dos dados. Pela estatística do teste ver-se que existe mais de 90\% (Alpha de Cronbach's = 0,9233) de confiabilidade nas respostas obtidas, o que é considerado muito bom.

$\mathrm{Na}$ Tabela 2 encontram-se os resultados quanto ao grau de satisfação dos moradores da Colônia de Pescadores Z7, no que diz respeito à - imagem global da EMPAER.

Tabela 2 - Satisfação em relação à imagem global da organização

\begin{tabular}{lccccc}
\hline \multicolumn{1}{c}{ Questões (Bloco 1) } & Média & $\begin{array}{l}\text { Desvio- } \\
\text { Padrão }\end{array}$ & $\begin{array}{c}\text { Quartil } \\
\text { Inferior }\end{array}$ & Mediana & $\begin{array}{c}\text { Quartil } \\
\text { Superior }\end{array}$ \\
\hline 2.1. Desempenho da organização: & 3,24 & 1,18 & 2 & 3 & 4 \\
\hline $\begin{array}{l}\text { 2.2. Colaboradores que lidam com os } \\
\text { pescadores no local de atendimento } \\
\text { (presencial): }\end{array}$ & 3,48 & 1,29 & 3 & 4 & 4 \\
\hline 2.3. Atendimento por telefone: & 3,19 & 1,44 & 2 & 3 & 5 \\
\hline $\begin{array}{l}\text { 2.4. Igualdade de tratamento praticado } \\
\text { no atendimento aos pescadores: }\end{array}$ & 3,71 & 1,10 & 3 & 4 & 5 \\
\hline $\begin{array}{l}\text { 2.5. Atendimento recebido pelos } \\
\text { funcionários da EMPAER: }\end{array}$ & 3,48 & 1,47 & 3 & 4 & 5 \\
\hline $\begin{array}{l}\text { 2.6. Melhorias implementadas } \\
\text { recentemente na organização: }\end{array}$ & 2,86 & 1,11 & 2 & 3 & 4 \\
\hline Resumo Geral das Respostas & 2,83 & 0,40 & 3 & 3 & 3 \\
\hline Fonte: dadosda pesqisa
\end{tabular}

Fonte: dados da pesquisa 
Em grande medida percebe-se que a satisfação dos respondentes em relação à imagem global do órgão não indica se esses estão mais satisfeitos ou insatisfeitos, com efeito, estes têm uma percepção ligeiramente neutra ou indiferente, conforme demonstra o resumo das estatísticas descritivas. Ademais, a pior satisfação diz respeito às - melhorias implementadas recentemente pela EMPAER -, ao contrário a melhor satisfação é quanto à - igualdade de tratamento praticado no atendimento aos pescadores.

Pressupõe-se, que isso se deve ao perfil de comprometimento da organização, que busca atingir todas as metas estabelecidas pelos programas sociais, porém possui força de trabalho reduzida, que por vezes dificultam o atendimento necessário para abranger o público cadastrado no programa MDA no mercado local. De modo geral, a organização executa suas atividades voltadas para visitas diárias ou semanais, dentro da rotina condizente com as necessidades dos pescadores, tendo em vista que o programa requer a assistência de forma integrada. A organização executa suas atividades buscando fazer visitas diárias, ou semanais, dentro da rotina condizente com as necessidades dos pescadores, tendo em vista que o programa requer a assistência de forma integrada.

Diante disso, sugere-se que algumas políticas de gestão e ordenamento pesqueiro possuem problemas como a falta de recursos financeiros e humanos, que são reportados como as principais causas para a pouca eficiência destas políticas. Esses resultados corroboram com os achados no estudo de Hellebrandt et al. (2012).

$\mathrm{Na}$ Tabela 3 encontram-se os resultados quanto à satisfação dos pescadores no que diz respeito à atuação da EMPAER em relação a envolvimento e participação em programas de financiamento. 
Tabela 3 - Satisfação com a atuação da EMPAER em relação ao envolvimento e participação em programas de financiamento

\begin{tabular}{lccccc}
\hline \multicolumn{1}{c}{ Questões (Bloco 2) } & Média & $\begin{array}{c}\text { Desvio- } \\
\text { Padrão }\end{array}$ & $\begin{array}{c}\text { Quartil } \\
\text { Inferior }\end{array}$ & Mediana & $\begin{array}{c}\text { Quartil } \\
\text { Superior }\end{array}$ \\
\hline $\begin{array}{l}\text { 3.1. Possibilidade de surgir melhorias } \\
\text { na qualidade de vida: }\end{array}$ & 2,57 & 1,12 & 2 & 3 & 3 \\
\hline $\begin{array}{l}\text { 3.2. As políticas públicas chegam com } \\
\text { frequência às famílias cadastradas nos } \\
\text { programas MDA/ATER: }\end{array}$ & 2,62 & 1,02 & 2 & 3 & 3 \\
\hline $\begin{array}{l}\text { 3.3. Os créditos auxiliam na melhoraria } \\
\text { do nível de renda familiar: }\end{array}$ & 3,10 & 1,14 & 3 & 3 & 4 \\
\hline $\begin{array}{l}\text { 3.4. O agente financeiro está } \\
\text { disponibilizando o recurso de acordo } \\
\text { com Plano Safra: }\end{array}$ & 3,05 & 1,02 & 2 & 3 & 3 \\
\hline $\begin{array}{l}\text { 3.5. Os produtores estão podendo } \\
\text { acessar o recurso em tempo hábil: }\end{array}$ & 2,81 & 1,03 & 2 & 3 & 4 \\
\hline $\begin{array}{l}\text { 3.6. Existem poucas políticas públicas } \\
\text { voltadas para a classe de trabalhadores } \\
\text { agrícolas: }\end{array}$ & 2,29 & 0,90 & 2 & 2 & 3 \\
\hline $\begin{array}{l}\text { 3.7. Os incentivos recebidos pelos } \\
\text { programas sociais são suficientes: }\end{array}$ & 2,57 & 0,98 & 2 & 3 & 3 \\
\hline $\begin{array}{l}\text { 3.8. O trabalho ofertado pela empresa } \\
\text { está em conformidade com o previsto } \\
\text { pelas políticas públicas: }\end{array}$ & 2,62 & 1,12 & 2 & 3 & 3 \\
\hline $\begin{array}{l}\text { 3.9. A parte burocrática "emperra" o } \\
\text { acesso aos créditos: }\end{array}$ & 2,29 & 1,15 & 1 & 2 & 3 \\
\hline $\begin{array}{l}\text { Resumo Geral das Respostas } \\
\text { Fonte: Dados da pesquisa. }\end{array}$ & 2,22 & 0,44 & 2 & 2 & 2 \\
\hline
\end{tabular}

É percebido pelo resumo geral das respostas, que existe um grau de insatisfação de modo homogêneo, entre os respondentes no tocante à atuação da EMPAER no envolvimento e participação em programas de financiamento às famílias da colônia. Parte-se do pressuposto, que isso seja devido ao desconhecimento em relação aos aspectos burocráticos e diretrizes estabelecidas nas políticas públicas voltadas às suas necessidades.

A EMPAER busca obedecer aos acordos de convênios firmados entre a instituição e o agente financeiro, acordados a priori no MCR - Manual de Crédito Rural. Complementarmente, os respondentes indicam que o agente financeiro informa sobre a disponibilidade de recurso do Plano Safra, contudo não existe interesse por parte dos mesmos, devido às exigências de garantias, aval cruzado, restrições envolvidas na emissão dos documentos exigidos pela empresa, além do valor financeiro da operação ser considerado irrisório para contratação (p.ex., questões 3.6 e 3.9). Além disto, ressalta-se o fato de que as políticas públicas para serem acessadas, precisariam ser incrementadas nos modelos sócios, econômicos e culturais, o que requer do gestor, agente de crédito e Ater, buscarem alinhar seus interesses e perspectivas.

A maioria dos entrevistados considera que a burocracia relacionada a exigências na documentação, dificulta o acesso, desde orçamentos, até assinatura de contratos. Além disso, as políticas sociais exigem certo grau de controle no acesso aos créditos, que pode gerar conflitos sociais de interesse ( $p$. ex. questões 3.5 e 3.7). Grande parte da insatisfação dos respondentes, quanto a questões que envolvam os serviços prestados pela EMPAER, e às políticas públicas de agricultara familiar, é, com efeito, devido às limitações burocráticas impostas aos beneficiários. 
Tal fato pode ser explicado pelo não atendimento aos requisitos exigidos pelas normas, e diretrizes de crédito rural da lei da ATER, ou das orientações do MCR Manual de Crédito Rural.

$\mathrm{Na}$ mesma linha dos resultados encontrados no estudo de Hellebrandt (2012, p. 35), "percebe-se a diversidade de conflitos que permeia a atividade pesqueira e na sequência, a quantidade de políticas públicas com foco na atividade pesqueira, hora mais voltada à exploração do recurso, hora mais voltada aos aspectos sociais para os pescadores". Complementa ainda "que as poucas políticas públicas pesqueiras de caráter ambiental são menos eficientes na prática do que seus textos propõem". Assim, alguns conflitos da pesca possuem em sua raiz uma intricada relação com as políticas públicas (HELLEBRANDT, 2012, p. 92).

$\mathrm{Na}$ Tabela 4 encontram-se os resultados quanto à satisfação dos pescadores no que diz respeito à acessibilidade a EMPAER.

Tabela 4 - Satisfação em relação à acessibilidade a EMPAER

\begin{tabular}{|c|c|c|c|c|c|}
\hline Questões (Bloco 3) & Média & $\begin{array}{l}\text { Desvio- } \\
\text { Padrão }\end{array}$ & $\begin{array}{l}\text { Quartil } \\
\text { Inferior }\end{array}$ & Mediana & $\begin{array}{c}\text { Quartil } \\
\text { Superior }\end{array}$ \\
\hline $\begin{array}{l}\text { 4.1. Localização do serviço: } \\
\text { proximidade de transportes públicos: }\end{array}$ & 3,19 & 1,50 & 2 & 3 & 5 \\
\hline $\begin{array}{l}\text { 4.2. Facilidade de estacionamento do } \\
\text { automóvel perto do local de } \\
\text { atendimento: }\end{array}$ & 3,38 & 1,40 & 2 & 4 & 5 \\
\hline $\begin{array}{l}\text { 4.3. Nível de acessibilidade (rampas de } \\
\text { acesso, elevadores): }\end{array}$ & 2,90 & 1,37 & 2 & 3 & 4 \\
\hline 4.4. Horário de atendimento: & 3,76 & 0,70 & 3 & 4 & 4 \\
\hline $\begin{array}{l}\text { 4.5. Informação disponível no local de } \\
\text { atendimento: }\end{array}$ & 3,00 & 1,05 & 2 & 3 & 3 \\
\hline $\begin{array}{l}\text { 4.6. Sistemas de divulgação das } \\
\text { atividades/informações: }\end{array}$ & 3,24 & 1,00 & 3 & 3 & 4 \\
\hline $\begin{array}{l}\text { 4.7. Existência de uma linha telefônica } \\
\text { para esclarecimento de } \\
\text { atendimento/dúvidas: }\end{array}$ & 3,19 & 1,50 & 2 & 3 & 4 \\
\hline $\begin{array}{l}\text { 4.8. Nível de simplificação dos } \\
\text { formulários (clareza da linguagem, } \\
\text { acessibilidade, facilidade de } \\
\text { preenchimento): }\end{array}$ & 3,29 & 1,23 & 3 & 3 & 4 \\
\hline $\begin{array}{l}\text { 4.9. Informações disponíveis on-line } \\
\text { site (pagamentos): }\end{array}$ & 2,81 & 1,03 & 2 & 3 & 3 \\
\hline $\begin{array}{l}\text { 4.10. Existência de serviços disponíveis } \\
\text { on-line (Laboratório): }\end{array}$ & 2,76 & 1,14 & 2 & 3 & 4 \\
\hline Resumo Geral das Respostas & 2,70 & 0,48 & 2,25 & 3 & 3 \\
\hline
\end{tabular}

Fonte: dados da pesquisa.

Ligeiramente, existe um consenso entre os respondentes referente à acessibilidade à EMPAER. Neste caso, para quase a totalidade daqueles, a acessibilidade à empresa é algo indiferente. Consideraram-se mais satisfeitos com apenas dois dos itens analisados. A localização, dado à facilidade de estacionamento de veículos próximo ao local de atendimento e horário de atendimento (p. ex, questões 4.2 e 4.4).

Embora, a empresa procure estar em conformidade com a lei da melhor idade, e dos portadores de necessidade especiais, isso é realizado de forma parcial e incompleta. Possivelmente como a grande maioria dos respondentes não possui computadores em casa, e desconhecem esse meio, deixam de otimizar seu tempo, 
e também da própria EMPAER, haja vista algumas informações podem ser obtidas diretamente na página da empresa. Adicionalmente, a organização presta assistência de campo e contata-se diretamente com a entidade que representa a categoria, prestando informações diversas, que são oficializadas e fixadas em mural público da sede (Colônia), embora não sejam visualizadas pela maioria do público atendido e interessado.

$\mathrm{Na}$ Tabela 5, encontram-se os resultados quanto à satisfação dos pescadores no que diz respeito aos produtos e serviços oferecidos pela EMPAER.

Tabela 5 - Satisfação global em relação aos produtos e serviços oferecidos pela EMPAER

\begin{tabular}{|c|c|c|c|c|c|}
\hline Questões (Bloco 4) & Média & $\begin{array}{l}\text { Desvio- } \\
\text { Padrão }\end{array}$ & $\begin{array}{l}\text { Quartil } \\
\text { Inferior }\end{array}$ & Mediana & $\begin{array}{l}\text { Quartil } \\
\text { Superior }\end{array}$ \\
\hline 5.1. Produtos entregues: & 2,86 & 1,20 & 2 & 3 & 4 \\
\hline $\begin{array}{l}\text { 5.2. Atendimento no serviço de ATER } \\
\text { (Assistência Técnica) presencial: }\end{array}$ & 3,29 & 1,15 & 3 & 3 & 4 \\
\hline 5.3. Serviços prestados: & 3,19 & 0,87 & 3 & 3 & 4 \\
\hline $\begin{array}{l}\text { 5.4. Clareza das informações } \\
\text { prestadas: }\end{array}$ & 3,19 & 0,93 & 3 & 3 & 4 \\
\hline $\begin{array}{l}\text { 5.5. Qualidade dos esclarecimentos } \\
\text { prestados por telefone: }\end{array}$ & 3,29 & 0,85 & 3 & 3 & 4 \\
\hline $\begin{array}{l}\text { 5.6. Equipamentos disponibilizados } \\
\text { suficientes para realização de } \\
\text { atividades: }\end{array}$ & 3,00 & 1,41 & 1 & 3 & 4 \\
\hline $\begin{array}{l}\text { 5.7. Qualidade dos esclarecimentos } \\
\text { prestados presencialmente: }\end{array}$ & 3,48 & 0,81 & 3 & 4 & 4 \\
\hline $\begin{array}{l}\text { 5.8. Qualidade dos produtos/serviços } \\
\text { (correspondência com o esperado): }\end{array}$ & 3,05 & 1,02 & 2 & 3 & 4 \\
\hline 5.9. Atendimento solicitado: & 3,33 & 1,20 & 2 & 3 & 4 \\
\hline $\begin{array}{l}\text { 5.10. Tempo de resposta das } \\
\text { reclamações }\end{array}$ & 2,76 & 1,41 & 1 & 3 & 4 \\
\hline $\begin{array}{l}\text { 5.11. Ofertados dos serviços prestados } \\
\text { para a qualidade de vida dos } \\
\text { moradores: }\end{array}$ & 3,05 & 1,20 & 2 & 3 & 4 \\
\hline Resumo Geral das Respostas & 2,81 & 0,40 & 3 & 3 & 3 \\
\hline
\end{tabular}

De modo análogo a alguns dos blocos de questões anteriores, neste bloco, enxerga-se uma predominação de repostas com uma escala maior de indiferença, como mostra o resumo geral das respostas.

Os itens 5.7, qualidade dos esclarecimentos prestados presencialmente, e 5.9, satisfação em relação ao atendimento solicitado, são aqueles que apresentaram maiores escalas de satisfação. Esses itens são considerados os mais relevantes, devido, sobretudo, pela atuação da assistência técnica da EMPAER, ser realizada de forma condizente com as necessidades do público, e em conformidade com os aspectos legais.

Percebe-se que os respondentes se consideram insatisfeitos com apenas dois dos itens analisados, sendo: 5.1, satisfação global com os produtos entregues, e 5.10, satisfação em relação ao tempo de resposta das reclamações. Isso pode justificar-se, pela existência de falhas no atendimento que interferem nos produtos que são entregues aos pescadores; bem como pela quantidade insuficiente de funcionários para a demanda de reclamações realizadas, visto que o escritório local não possui secretária e o quadro de técnicos é resumido. 
Os demais itens apresentaram médias semelhantes, e não se destacam dentre os demais. Considera-se pertinente ressaltar a respeito dos itens, 5.9 e 5.11, em que a maioria dos respondentes avaliou que é fundamental, a EMPAER continuar cumprindo a sua missão responsavelmente, respeitando, o agente de crédito, produtor (pescadores), de modo a auxiliar as famílias da colônia na manutenção de suas atividades, as quais também passam pela observância das recomendações legais.

A fim de verificarmos qual dentre os quatros blocos de questões carrega o melhor nível de informação, isto pé, que possibilite fazer-se uma conclusão geral sobre a percepção dos moradores, é aplicado, a análise das componentes principais (ACP), cujos resultados são ilustrados e apresentados na Figura 3, e também na Tabela 6, respectivamente.

A Figura 3 sinaliza que a componente com maior nível informacional, diz respeito a primeira componente, que carrega $73,38 \%$ das variâncias de todas as demais componentes em conjunto. Esta componente, e a segunda componente carregam um total de $83,91 \%$ das cargas informacionais. Nesta perspectiva, percebe-se que pela primeira componente, o terceiro bloco de questões, acessibilidade à organização. Não obstante, quando tomadas, a primeira e segunda componentes, o bloco de questões, envolvimento e participação em programas de financiamento, é aquela que carrega o maior nível de informação para análise da percepção dos moradores da Colônia de Pescadores Z, São Félix do Araguaia, MT, em relação à satisfação dos serviços prestados pela Empresa Mato-grossense de Pesquisa, Assistência e Extensão Rural (EMPAER). Logo, as perspectivas referentes à obtenção de crédito por meio de programas de financiamento a agricultara rural, têm sido no momento, um dos principais pontos, que podem ser analisados minuciosamente pela entidade EMPAER. Analogamente, a Tabela 6 mostra os coeficientes dos autovetores das componentes principais que levam as mesmas conclusões.

Figura 3 - Percentagem da variância das componentes principais

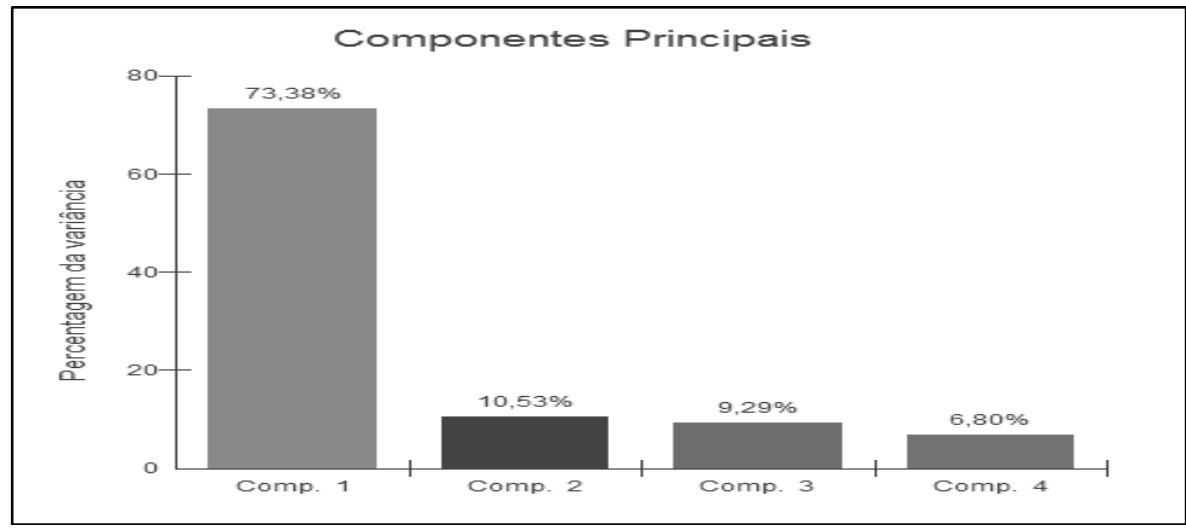

Fonte: dados da pesquisa. 
Tabela 6 - Coeficientes dos autovetores das componentes principais

\begin{tabular}{ccccc}
\hline $\begin{array}{c}\text { Autovetores } \\
\text { (Coeficientes) }\end{array}$ & B1 & B2 & B3 & B4 \\
\hline Comp. 1 & 0,4916 & 0,4995 & 0,5127 & 0,4959 \\
Comp. 2 & $-0,6762$ & 0,6512 & 0,2467 & $-0,2406$ \\
Comp. 3 & $-0,4014$ & 0,0457 & $-0,437$ & 0,8036 \\
Comp. 4 & $-0,3741$ & $-0,5695$ & 0,6967 & 0,2243 \\
\hline
\end{tabular}

Legenda: B1 = Imagem Global da Organização; B2 = Envolvimento e Participação em Programas de Financiamento; B3 = Acessibilidade à Organização; B4 = Produtos e Serviços Ofertados pela Empresa.

Fonte: Dados da pesquisa.

\section{CONSIDERAÇÕES FINAIS}

Nesta pesquisa buscou-se identificar o nível de satisfação dos moradores da Colônia de Pescadores Z7, localizada no município de São Félix do Araguaia MT, quanto aos serviços prestados pela EMPAER, a fim de aperfeiçoar qualidade dos trabalhos guiados por este órgão na efetivação de políticas públicas de desenvolvimento rural sustentável no Estado mato-grossense.

Para tanto, foi aplicado a 21 usuários do programa oferecido pela EMPAER, um questionário semiestruturado contendo 42 questões relacionadas ao perfil dos respondentes, a imagem global da organização, ao envolvimento e participação de créditos, a acessibilidade, e aos produtos e serviços oferecidos. O questionário é um dos instrumentos que mede a qualidade dos serviços públicos, utilizado pela Estrutura Comum de Avaliação (CAF).

Após a análise dos resultados, verificou-se que os pescadores integrantes do programa MDA/ATER, residem na Colônia por mais de 10 anos e dependem, na maioria, exclusivamente da atividade de pesca para autosubsistência e sustento da família. Embora não seja o foco desta pesquisa, supõe-se que essa dependência ocorre devido ao baixo grau de escolaridade dos mesmos ou a falta de opções de trabalho no município e ao perfil socioeconômico da região.

Em relação às quatro categorias de análise, verificou-se que a organização atende as necessidades dos usuários, por meio de uma assistência integrada, com informações úteis, atendimento adequado, boa localização e acesso, e quanto aos produtos e serviços oferecidos pela EMPAER, na sua maioria. Em contrapartida, os respondentes consideram-se insatisfeitos em relação às políticas públicas e créditos, devido principalmente às limitações legais e burocráticas impostas aos beneficiários.

Desse modo, embora o programa possua, na percepção dos usuários, algumas falhas relacionadas à burocracia que envolve a liberação de crédito rural, confere benefícios que deveriam ser mantidos e melhorados em conformidade com as mudanças das necessidades dos indivíduos envolvidos. Assim, percebe-se que a existência do programa coordenado pela EMPAER é essencial para a sobrevivência das famílias assistidas, além de contribuir para a manutenção da economia do município de pequeno porte.

Os resultados encontrados sugerem que o desenvolvimento de políticas públicas de amparo à atividade pesqueira pode contribuir para o fortalecimento da atividade, a geração de emprego e renda e a manutenção destas atividades, evitando a pesca predatória. Tais ações contribuem ainda para a sobrevivência dos pescadores, que tem na pesca a sua atividade de subsistência, bem como para com a preservação ambiental.

De modo geral, a política de assistência rural do município de São Félix do Araguaia, realizada por meio do projeto MDA/ATER, fornece serviço de assistência aos trabalhadores rurais, associando o aumento da produção agrícola com a 
qualidade de vida para os moradores das comunidades rurais. Em especial, esse projeto proporciona a preservação ambiental, contribuindo para a redução da pesca predatória e o esgotamento de recursos naturais, pois são respeitados períodos adequados para realização da pesca, bem como deve ser realizado o manejo adequado dos recursos naturais pelos pescadores inseridos no programa.

Sugere-se como futuras pesquisas, a análise de outros municípios matogrossenses na qual ocorra atuação da EMPAER através do programa aqui explorado, visando realizar comparações entre perfis populacionais, econômicos e geográficos existentes, possibilitando traçar um perfil das populações que possuem economia familiar rural e depende de políticas públicas voltadas à agricultura sustentável como forma de subsistência, bem como para incentivar o desenvolvimento do Estado de Mato Grosso.

\section{REFERÊNCIAS}

ABDALLAH, P. R. Atividade pesqueira no Brasil: política e evolução. 1998.148f. Tese (Doutorado em Ciências) - Programa de Pós-Graduação em Ciências, Universidade de São Paulo.

AGUIAR, N. F. P. O Modelo de gestão da qualidade CAF (estrutura comum de avaliação) - o papel da liderança. 2010. 112f. Dissertação (Mestrado em Gestão e Administração Pública), Universidade Técnica de Lisboa.

ASSIS, R. L. Desenvolvimento rural sustentável no Brasil: perspectivas a partir da integração de ações públicas e privadas com base na agroecologia. Revista Economia Aplicada, v. 10, n.1, p. 75-89, 2006.

AZEVEDO, N. T.; PIERRI, N. A política pesqueira no Brasil (2003-2011): a escolha pelo crescimento produtivo e o lugar da pesca artesanal. Revista Desenvolvimento e Meio Ambiente, v. 32, p. 61-80, dez. 2014.

BRUM, A. L.; LUFT, A. Aspectos da cadeia produtiva do milho e as relações comerciais nos estados do Rio Grande do Sul e Mato Grosso (1994/95-2005/06). Extensão Rural, Santa Maria, v. 15, n. 16, p. 117-153, 2008.

CAMPOS, A. R. S. Uma análise do turismo em mato grosso sob a ótica da matriz insumo-produto. 2010. 171f. Dissertação (Mestrado em Economia) Programa de Pós-Graduação em Economia, Universidade Federal de Mato Grosso.

CHAMY, P.; MALDONADO, W. Sustentabilidade social, econômica e ambiental de pequenos negócios: o caso da Cooperostra, Cananéia/SP. In: ENCONTRO BIENAL DA SOCIEDADE BRASILEIRA DE ECONOMIA ECOLÓGICA, 5, 2003, Caxias do Sul, RS.Anais... Rio de Janeiro: ECOECO, 2003, p. 1-24.

COLINNA, E. K. Análise crítica da rotulagem ambiental como elemento transformador da pesca artesanal. 2014. 93 f. Dissertação (Mestrado em Gerenciamento Costeiro), Programa de Pós-Graduação em Gerenciamento Costeiro, Universidade Federal do Rio Grande.

DELGADO, N.; G. Política econômica, ajuste externo e agricultura. In: LEITE, S. Políticas públicas e agricultura no Brasil. Rio Grande do Sul: UFGRS, 2001. 
FERRO, A. S.; LOPES, B. F.; GUTERRES, D. M. A.; LIMA, D. O.; CORTÊS, N. A.; ALMEIDA, V. M. Projeto vida nova: a subsistência da família rural. 2 ed. Cuiabá: EMPAER-MT, 2003.

FOLADORI, G. Avanços e limites da sustentabilidade social. Revista Paranaense de Desenvolvimento, n. 102, p. 103-113, 2002.

GOMES, I. Sustentabilidade social e ambiental na agricultura familiar. Revista de Biologia e Ciências da Terra, v. 5, n. 1, p. 1-18, 2004.

HELLEBRANDT, L. M. Conflitos da pesca artesanal da tainha na colônia Z3 e sua relação com as políticas públicas. 2012. 94f. Dissertação (Mestrado em Gerenciamento Costeio) - Programa de Pós-Graduação em Gerenciamento Costeiro, Universidade Federal do Rio Grande.

HELLEBRANDT, L.; ABDALLAH, P., R.; HELLEBRANDT, D.; BARBOSA, M. N.; SILVEIRA, L. S.; RAMOS, M. A. P. Avaliação de políticas públicas aplicadas à pesca artesanal no Brasil. In: ENCONTRO NACIONAL DA ANPPAS, 6., 2012, Belém, PA. Anais... São Paulo: ANPPAS, 2012, p. 1-18.

LAFORGA, G.; VIEIRA, A. O. Ação extensionista da EMPAER frente à nova PNATER: uma análise a partir do assentamento Guapirama, Campo Novo do Parecis - MT. In: SOBER- XLVI CONGRESSO DA SOCIEDADE BRASILEIRA DE ECONOMIA, ADMINISTRAC̣ÃO E SOCIOLOGIA RURAL, 46., 2008, Rio Branco, AC. Anais... Brasília-DF: SOBER: 2008, p.1-18.

MARQUES, P. E. M. Política agrícola, desenvolvimento rural e sustentabilidade. In: MARQUES, P. E. M. Política agrícola, desenvolvimento rural e sustentabilidade diálogo franco-brasileiro no âmbito da cooperação em ciências agrárias e florestais. Piracicaba: ESALQ/USP, 2010.

MORAES, M. D.; LAFORGA, G.; MARIMON JUNIOR, B. H.; MARIMON, B. S. Estratégias de difusão do conhecimento da pesquisa agropecuária da universidade do estado de Mato Grosso. Extensão Rural, Santa Maria, v. 18, n. 22, p. 29-66, 2011. Disponível em: < https://periodicos.ufsm.br/extensaorural/article/view/5574>. Acesso em: 26 out. 2016.

NOGUEIRA, V. M. Histórico: atual da Empresa Mato-grossense de Pesquisa, Assistência e Extensão Rural S/A-EMPAER. Disponível em: http://www.empaer.mt.gov.br/informativo/informativo.asp?cod=106. Acesso em: 15 mai. 2015.

REBOUÇAS, G. N.; FILARDI, A. C. L.; VIEIRA, P. F. Gestão integrada e participativa da pesca artesanal. Potencialidades e obstáculos no litoral do Estado de Santa Catarina. Revista Ambiente \& Sociedade, v. 9, n. 2, p.83-104, 2006.

SANTOS, G. M.; SANTOS, A. C. M. Sustentabilidade da pesca na Amazônia. Revista Estudos Avançados, v. 19, n. 54, p. 165-182, 2005.

SANTOS, M. J. Projeto alternativo de desenvolvimento rural sustentável. Revista Estudos Avançados, v. 15, n. 43, p. 225-238, 2001. 
SOUZA, C. B.; CAUME, D. J. Crédito rural e agricultura familiar no Brasil. In: SOBER- XLVI CONGRESSO DA SOCIEDADE BRASILEIRA DE ECONOMIA, ADMINISTRAÇÃO E SOCIOLOGIA RURAL, 46, 2008, Rio Branco, AC. Anais... Brasília-DF: SOBER: 2008, p.1-21.

SOUZA, M. A. A. A pesca artesanal na colônia São Pedro (Z3), Pelotas, RS. 2001. 98f. Dissertação (Mestrado em Economia Rural) - Programa de PósGraduação em Desenvolvimento Rural, Universidade Federal do Rio Grande do Sul. 